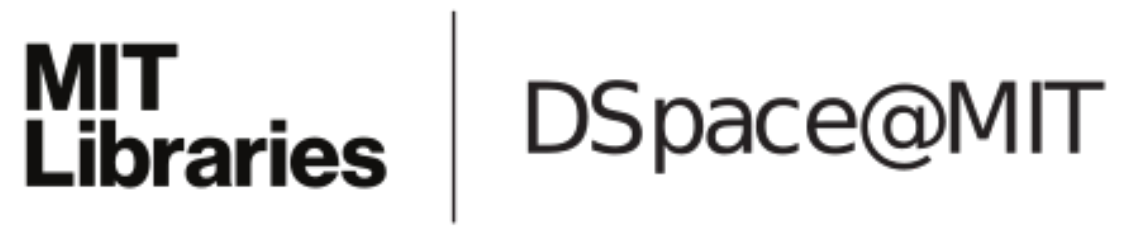

\author{
MIT Open Access Articles
}

Origins and Structure of Spike-Type Rotating Stall

The MIT Faculty has made this article openly available. Please share how this access benefits you. Your story matters.

Citation: Pullan, G., A. M. Young, I. J. Day, E. M. Greitzer, and Z. S. Spakovszky. “Origins and Structure of Spike-Type Rotating Stall." Volume 8: Turbomachinery, Parts A, B, and C (June 11, 2012)..

As Published: http://dx.doi.org/10.1115/GT2012-68707

Publisher: ASME International

Persistent URL: http://hdl.handle.net/1721.1/116390

Version: Final published version: final published article, as it appeared in a journal, conference proceedings, or other formally published context

Terms of Use: Article is made available in accordance with the publisher's policy and may be subject to US copyright law. Please refer to the publisher's site for terms of use. 


\section{ORIGINS AND STRUCTURE OF SPIKE-TYPE ROTATING STALL}

\author{
G.Pullan; A.M. Young, I.J. Day \\ Whittle Laboratory \\ University of Cambridge \\ $1 \mathrm{JJ}$ Thomson Avenue \\ Cambridge, CB3 ODY, UK \\ Email: gp10006@cam.ac.uk
}

\author{
E. M. Greitzer, Z. S. Spakovszky \\ Gas Turbine Laboratory \\ Massachusetts Institute of Technology \\ 77 Massachusetts Avenue \\ Cambridge, MA 02139
}

\begin{abstract}
In this paper we describe the structures that produce a spiketype route to rotating stall and explain the physical mechanism for their formation. The descriptions and explanations are based on numerical simulations, complemented and corroborated by experiments. It is found that spikes are caused by a loss of pressure rise capability in the rotor tip region, due to flow separation resulting from high incidence. The separation gives rise to shedding of vorticity from the leading edge and the consequent formation of vortices that span between the suction surface and the casing. As seen in the rotor frame of reference, near the casing the vortex convects toward the pressure surface of the adjacent blade. The approach of the vortex to the adjacent blade triggers a separation on that blade so the structure propagates. The above sequence of events constitutes a spike. The simulations show shed vortices over a range of tip clearances including zero. The implication is that they are not part of the tip clearance vortex, in accord with recent experimental findings. Evidence is presented for the existence of these vortex structures immediately prior to spike-type stall and, more strongly, for their causal connection with spike-type stall inception. Data from several compressors are shown to reproduce the pressure and velocity signature of the spike-type stall inception seen in the simulations.
\end{abstract}

\section{INTRODUCTION}

It has been known for more than a decade that there are two distinct routes to compressor rotating stall with different onset

\footnotetext{
*Visiting Associate Professor, MIT, July-Dec 2011
}

criteria for each [1]. One is through the growth of small amplitude (compared to the mean velocity) disturbances with length scale of the compressor circumference. The initial stages of this process are in accord with the linear-to-nonlinear wave evolution described by established theories of compressor instability, [2]. A second route, however, is through transient disturbances with much shorter length scale (several blade pitches), which, as detected by probes upstream of a blade row, are of large amplitude compared to the mean velocity and are not described by existing analyses. The disturbances in this second route have been called spikes, in reference to the sharp waveform they exhibit compared to the first type of disturbance. The phenomena responsible for the formation of such spikes are not well understood.

In this paper we define the fluid dynamic processes responsible for the occurrence and formation of spikes as a route to compressor rotating stall. It will be shown that the spike is linked to separation from the leading edge in the tip region. Further, spike stall has been found in axial compressors with tip clearance, axial compressors with tip shrouds (hence, no tip clearance or relatively rotating endwall), and in centrifugal compressor vaned diffusers. The implication we draw from these experimental results, and from the simulations, is that the proposed mechanism appears generic and applicable to a broad range of turbocompressors.

We emphasize the generic aspects in what follows, although there is an important caveat in that the circumstances which promote the leading edge separation in a specific situation do depend on the details of the turbomachinery. In this context a rough analogy can be made with the first route to instability. It is well- 
known that the conditions under which long length scale, small amplitude, disturbances grow into rotating stall are associated with operation on a positively sloped compressor pressure rise characteristic. That is the generic finding concerning long length scale disturbances. There are, however, multiple fluid dynamic processes by which this criterion can be achieved: increased blade loss, increased tip clearance flow blockage, increased deviation, or a combination of two or more of these. Which occurs depends on design specifics, and any or all can lead to a situation in which the pressure rise characteristic peaks. We will show that an analogous set of circumstances is present in the description of spike stall, in that there are many possible causes for the increase in incidence required to trigger a leading edge separation.

The organization and scope of the paper is as follows. We first show experimental measurements from axial compressors with tip clearance and with a shrouded tip, and from a centrifugal compressor with vaned diffuser, as examples of spike stall. Following that we introduce the proposed vortex behavior and the structure of the spike to address, in qualitative terms, the question of "what is a spike?". A series of unsteady simulations of the NASA $\mathrm{E}^{3}$ Rotor B are interrogated to provide insight into the quantitative nature of spike stall, with the understanding gained then applied to interpret further computations and detailed experimental information from an additional compressor.

\section{NOMENCLATURE}

$c_{x} \quad$ Axial chord

$r_{t} \quad$ Tip radius

$p \quad$ Pressure

$p_{01} \quad$ Rotor inlet stagnation pressure

$t \quad$ Time

$U_{t} \quad$ Tip speed

$x \quad$ Axial distance, measured from the leading edge

$\rho$ Density

$\tau \quad$ Blade passing period

$\Omega \quad$ Rotor angular velocity

$\widetilde{\Delta p} \quad$ Pressure coefficient $=\frac{p-p_{01}}{\frac{1}{2} \rho U_{t}^{2}}$

$\widetilde{\omega_{r}} \quad$ Non-dimensional radial vorticity $=\frac{\omega_{r}}{U_{t} / r_{t}}$

$\psi_{T S} \quad$ Total-to-static pressure rise coefficient $=\frac{p_{\text {exit }}-p_{01}}{\frac{1}{2} \rho U_{t}^{2}}$

\section{EXPERIMENTAL INFORMATION ON SPIKE STALL}

Spike type rotating stall inception is known to occur in axial flow compressors near the tip of the rotor blade leading edge. The stall onset is apparent in time-resolved casing static pressure measurements from probes at different circumferential locations upstream of a rotor. Figure 1 is an example, showing data from five pressure transducers in an MHI single-stage axial compressor with hub-to-tip ratio of 0.7 and rotor blade tip-clearance of $1 \%$ span. The spike disrupts the blade passing waveforms by a sudden rise in pressure, followed by a rapid pressure drop. Similar traces have been reported in [3-5] and elsewhere. The pattern grows in amplitude and length scale as it travels around the circumference at approximately $80 \%$ of rotor speed before evolving into rotating stall.

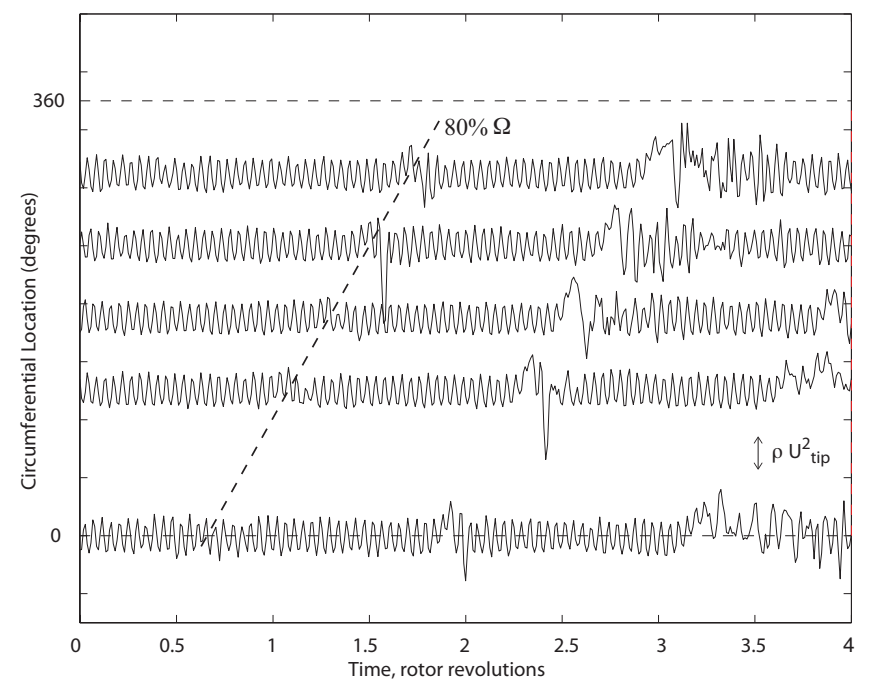

FIGURE 1: Spike stall inception in MHI single stage axial compressor with rotor tip clearance of $1 \%$ span. [Data courtesy of Takasago R\&D Center, MHI].

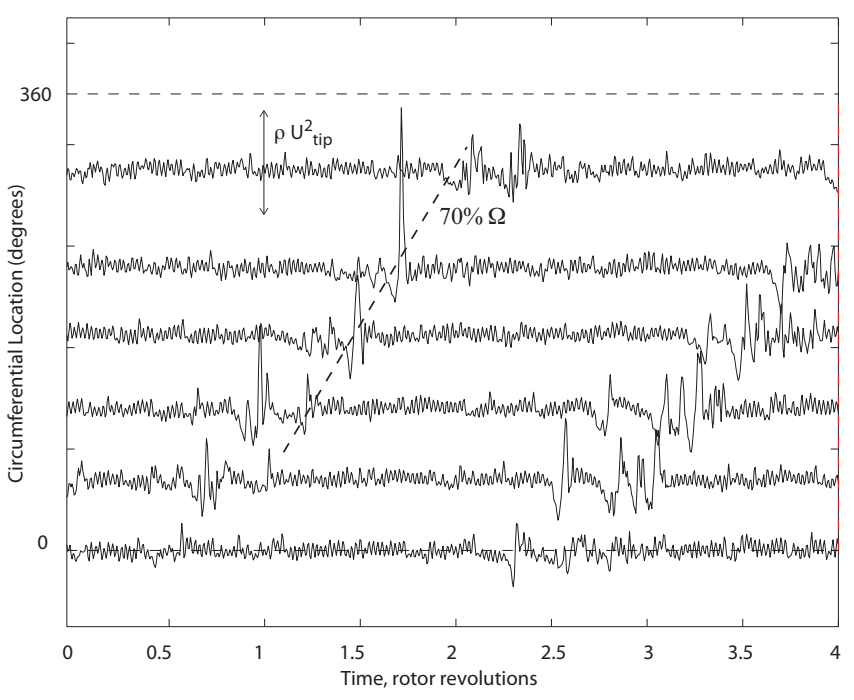

FIGURE 2: Spike stall inception in the MIT single stage axial compressor with tip shrouded rotor, [6].

Although it has been conjectured that tip clearance flow is necessary for spike formation, there are at least two sets of experiments that show this need not to be the case, the first on a tip 


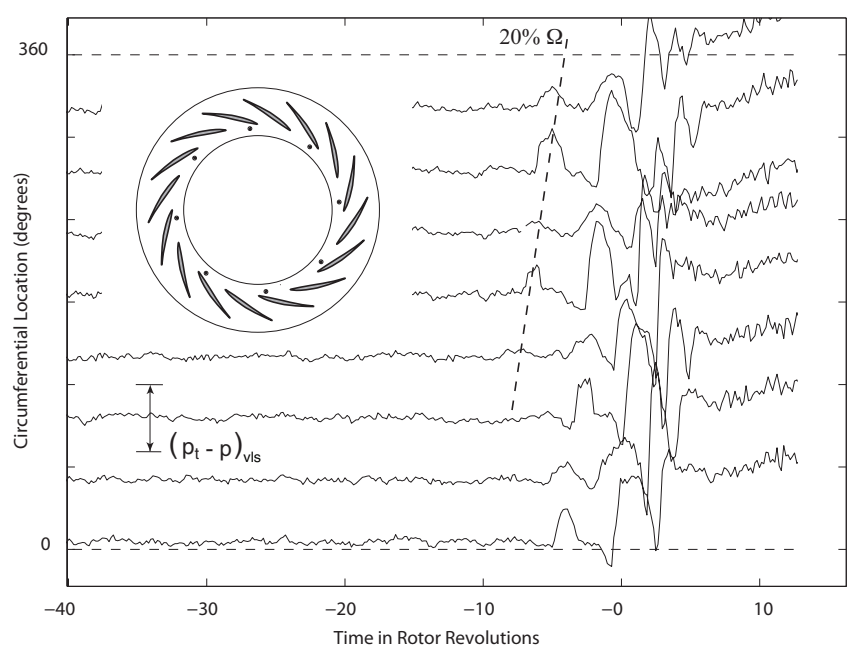

FIGURE 3: Spike stall inception in the vaned diffuser of a centrifugal compressor, [7]

shrouded axial compressor and the second on a centrifugal compressor with vaned diffuser. In the first of these, a single-stage axial compressor at MIT was run with a sheet metal shroud to prevent tip leakage [6] and data was taken on the type of stall onset. Figure 2 shows the resulting time-resolved casing static pressures during throttle ramps into stall. Stall inception in the shrouded compressor is seen to consist of spike-like disturbances that rotate around the annulus at about $70 \%$ of rotor speed and evolve into a full-span stall cell.

In the second set of experiments measurements carried out in a centrifugal compressor vaned diffuser suggest that spike-type stall precursors occur near the leading edge of shrouded diffuser vanes [7], although the precursors are larger in spatial extent and slower in rotation rate than in axial machines, consistent with the larger blade pitch. Figure 3 shows the time-resolved shroud static pressures, at eight locations around the circumference, at a radial station between the impeller and the diffuser. The disturbance propagates at about $20 \%$ of rotor speed ${ }^{1}$. The sudden rise in pressure followed by the rapid pressure drop can (again) be seen. Unsteady calculations reveal that flow separation at the diffuser leading edge, caused by high incidence near the shroud, leads to reversed radial flow, allowing vorticity shed from the leading edge to move inwards and recirculate around the circumference. As blockage accumulates, the spikes grow, leading to flow breakdown into rotating stall [8].

In support of the comments in the Introduction, therefore, the inference we draw is that spike-like pre-stall patterns occur in centrifugal as well as axial turbomachinery and that blade tip leakage flow is not a necessary condition for their formation.

\footnotetext{
${ }^{1}$ This speed is measured in the same (absolute) frame of reference as the stalling blade row. For stall inception occurring in a rotor, a spike travelling at $80 \%$ of wheel speed in the absolute frame has a speed of $20 \%$ in the relative frame.
}

\section{A CONCEPTUAL PICTURE OF SPIKE FLOW STRUC- TURE}

While the above two sections give information on the flows in which spikes form, and while there are descriptions of the conditions that accompany this formation $[1,4,9]$, our perspective is that there exists no description of the fluid dynamic events which are causally linked with the spike creation. Providing this link, based on interrogations of numerical simulations and experimental measurements, is the main contribution of this paper.

Most of the calculation results to be presented are instantaneous snapshots of pressure and radial vorticity near the compressor casing. Anticipating those results we state that they allow a conceptual picture to be built up of the key features of the vortical spike structure as depicted in Fig. 4: i) High incidence results in a separation from the leading edge in the outer part of the blade; (ii) The vorticity shed by this separation forms a vortex tube that spans from blade to casing as was suggested by Inoue et al. [10]; (iii) The upper end of the vorte ${ }^{2}$ is on the casing and the lower end is on the blade. The convection of the vortex, as seen in the rotor frame of reference, is indicated by the arrows; (iv) a new separation then forms on the next blade and the spike propagates.

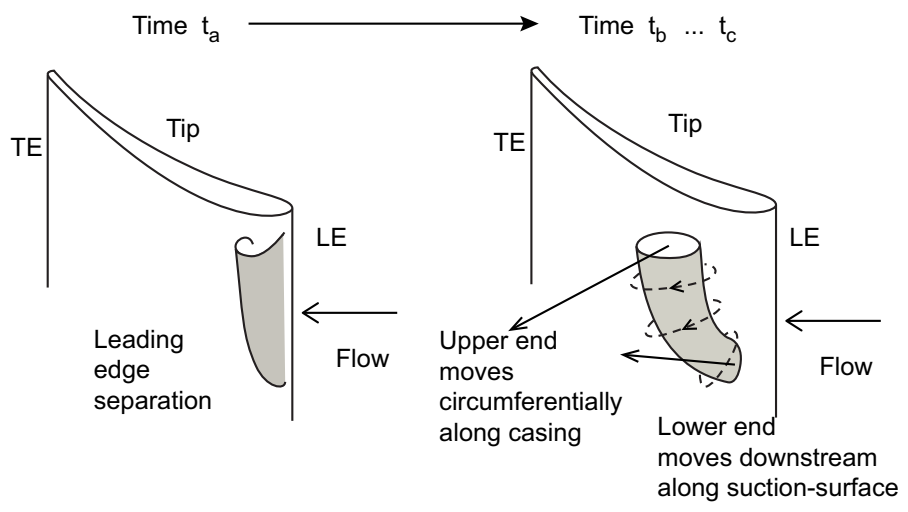

FIGURE 4: The vortical structure and propagation of the spike

Simulations both with and without clearance show this structure, and we thus infer that the formation of, and vorticity source for, the vortex shed from the leading edge is not associated with the tip clearance vortex ${ }^{3}$.

Figure 5 is a sketch of the time evolution of the vortex skeleton associated with this behavior. It shows vortex filaments near

\footnotetext{
${ }^{2}$ Vortex lines cannot end in a fluid, and what we have drawn is a section of a vortex tube. The vortex lines within the tube continue in thin layers on the casing and on the rotor (at these surfaces they must be tangential to the surface) rather than in the form of a discrete vortex. For simplicity we have not drawn the vortex lines outside of the section of the tube that is shown.

${ }^{3}$ Again, the conditions that lead to the separation and the vortex do depend on the details of the compressor and, similarly, the presence and size of the clearance vortex will have an influence on when the spikes will occur.
} 
the blade leading edge region, looking upstream, roughly along the blade stagger angle. The blades are drawn as heavy vertical lines. The sketch on the left side of Fig. 5 shows the passage at three time instants ${ }^{4}$. At time $t_{a}$ there is no separation, and the vortex filaments are close to the suction surface. At time $t_{b}$ the upper part of the filament (and the surrounding vortex tube) has detached from the suction side, and at time $t_{c}$ the upper part has moved further away from the suction surface. In terms of image vorticity, as in the right side sketch of Fig. 5, the configuration at time $t_{c}$ appears as a vortex ring, with sense of vorticity implying upstream propagation, given an appropriate combination of low enough onset velocity and strong enough circulation.
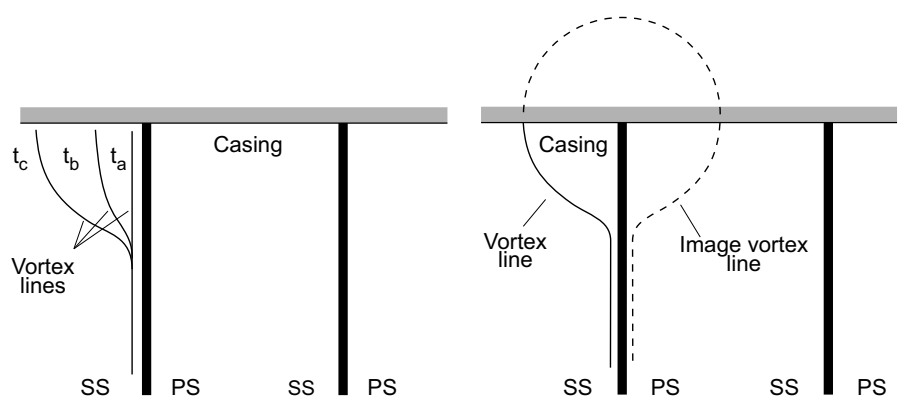

FIGURE 5: Vortex filament evolution from leading edge separation (left), and image system showing vortex ring (right). View is upstream along stagger angle.

The conceptual picture of the spike that we put forward appears to apply to the different geometries examined; axial compressors with tip clearance, tip shrouded axial compressors, and centrifugal compressors. It is also consistent with the simulations, with the experimental findings both overall (the view of spikes as an incidence-related phenomenon localized to the tip region) and detailed (the characteristic wave form of pressure transducers upstream of the leading edge, and the casing static pressure field measured by arrays of transducers).

\section{SUMMARY OF THE COMPUTATIONAL APPROACH}

Information on the computational method is provided in the Appendix and only a brief summary is given here. The computations were performed using Turbostream [11], a structured multiblock URANS code based on the algorithms developed by Denton [12]. A single equation Spalart-Allmaras turbulence model was used. All computations were performed on graphics processing units, allowing an order of magnitude reduction in runtime compared to running the same calculations on conventional processors.

\footnotetext{
${ }^{4}$ These times correspond to the computations in Fig. 13(a), (b) and (c), as will be described
}

\section{$E^{3}$ ROTOR B SIMULATIONS Introduction}

The NASA E ${ }^{3}$ Rotor B is used to investigate the fluid structures at spike onset. This rotor is chosen because it has been the subject of a previous study of spike-type stall inception, [9], the information on the geometry is public, and it is representative of a range of machines of technological interest. The rotor is characterised by the parameters listed in Table 1 and detailed information is provided in [13].

\begin{tabular}{|l|c|}
\hline Design flow coefficient $V_{x} / U_{t}$ & 0.41 \\
Design stage pressure rise coefficient $\Delta p_{0} / 0.5 \rho U_{t}^{2}$ & 0.56 \\
Hub to tip radius ratio $r_{h} / r_{t}$ & 0.85 \\
Tip diameter & $1524 \mathrm{~mm}$ \\
Number of rotors & 54 \\
Rotational speed & $722 \mathrm{rpm}$ \\
\hline
\end{tabular}

TABLE 1: Design parameters for the $\mathrm{E}^{3}$ Rotor $\mathrm{B}$ compressor

The computations are presented in order of increasing complexity: a linear cascade of translating $\mathrm{E}^{3}$ Rotor $\mathrm{B}$ tip profiles; $\mathrm{E}^{3}$ Rotor B without tip clearance; and $\mathrm{E}^{3}$ Rotor $\mathrm{B}$ with tip clearance. This progression has two advantages. First, it allows the details of the spike to be diagnosed first in situations with fewer interacting phenomena than when tip clearance is present and, second, it facilitates the identification of mechanisms common to all cases.

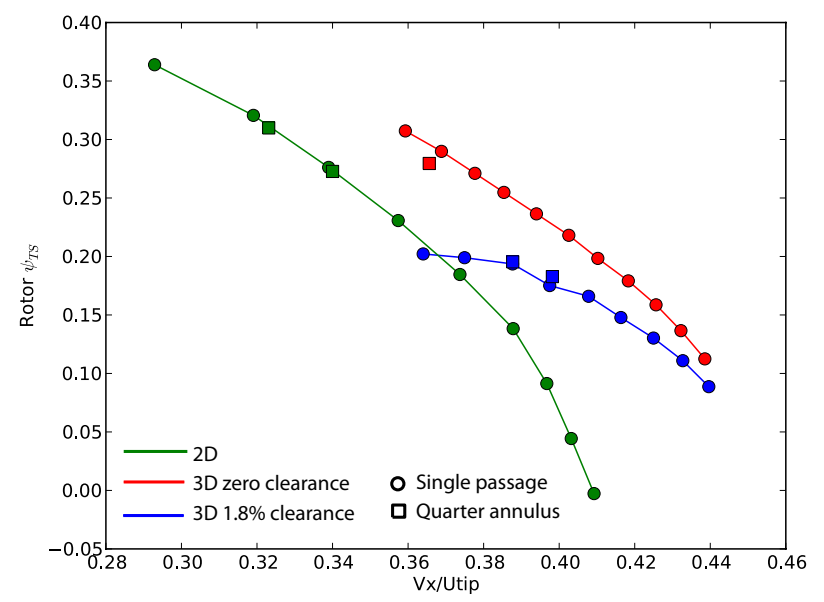

FIGURE 6: Computed total-to-static characteristics for the $\mathrm{E}^{3}$ Rotor B

Figure 6 shows computed total-to-static characteristics for the three $\mathrm{E}^{3}$ Rotor $\mathrm{B}$ geometries. The circles denote unsteady single passage computations, and the squares denote computations 
carried out using a domain of a quarter of the circumference (for blade periodicity, 93 degrees). Only stable operating points are indicated. Three observations can be made. First, in each case, the characteristic has a negative slope at the stall point and we therefore expect the simulations to take the spike route to rotating stall. Second, the quarter-sector calculations stall at a higher flow coefficient than the single passage computations. This implies that a sufficient number of passages must be modelled in order to resolve the early stages of spike stall inception. The pressure rise associated with the initial spike is approximately 2 or 3 pitches in circumferential extent and at least double this number of passages are likely to be required to resolve the formation of a spike. Third, although the two-dimensional geometry appears to stall at a very different condition, the stall incidence (pitch-wise averaged at 35\% of axial chord upstream of the rotor, at $95 \%$ span for the 3D cases) differs by less than 1 degree for all three geometries.

\section{Two-dimensional simulations}

Based on the evidence that tip clearance is not required for spike formation, the first set of simulations we explore are for a two-dimensional linear cascade of $\mathrm{E}^{3}$ tip section profiles. Following the procedure described in the Appendix, an unsteady calculation of a single passage domain was used to identify the stability limit. Then, a "full wheel" (periodic over 54 passages) domain was used, with the flow coefficient gradually reduced until stall onset. To initiate stall at a known location for detailed analysis, four adjacent blades were restaggered (permanently) by 1 degree to increase their incidence.

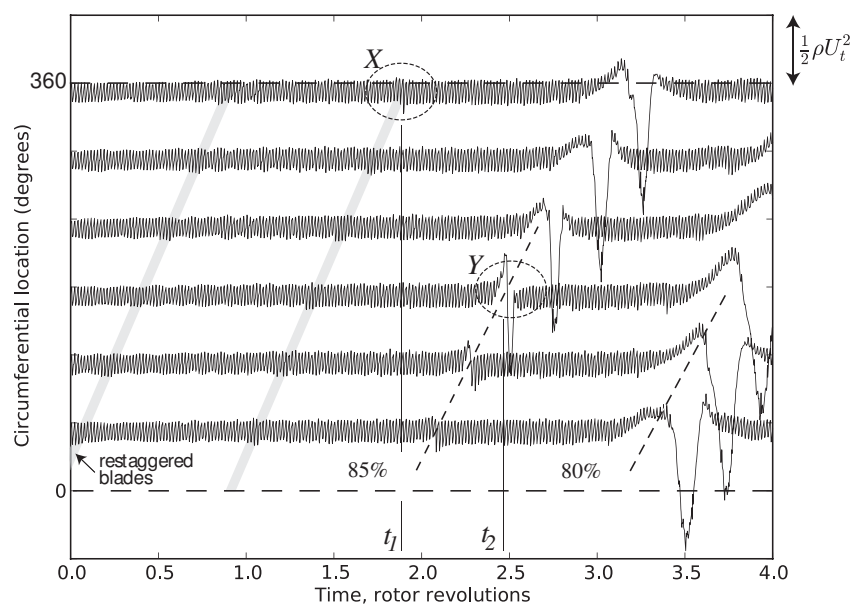

FIGURE 7: Spike stall inception in $2 \mathrm{D}^{3}$ tip profile cascade computation

Figure 7 shows a set of computed non-dimensional static pressure traces at six equi-spaced locations across the 54 passages, $10 \%$ of axial chord upstream of the leading edge. A per-
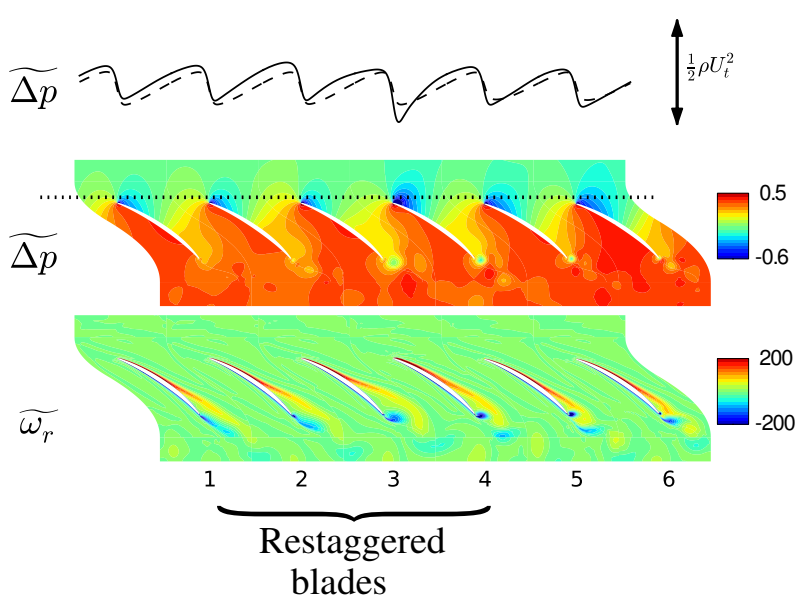

(a) $t=t_{1}=1.9$ revs
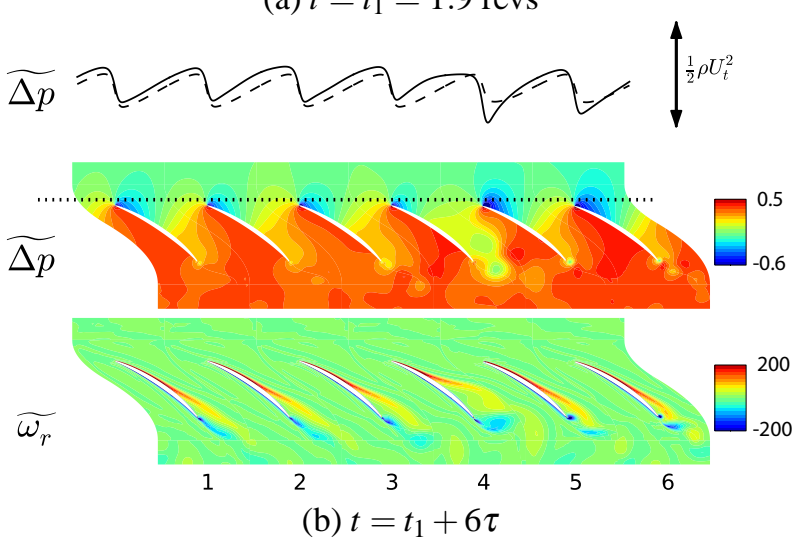

FIGURE 8: Blade loading perturbation caused by suction-surface separation in $2 \mathrm{D} \mathrm{E}^{3}$ tip profile cascade

turbation in the upstream potential field of the blades is first detected, at the restaggered blades, at time $t_{1}$. Within half a rotor revolution, this disturbance has grown and the pressure trace now shows the characteristic up-down waveform of a spike.

The flow field accompanying the initial disturbance (time $t_{1}$, location ' $\mathrm{X}$ ') and spike (time $t_{2}$, location ' $\mathrm{Y}$ ') are now examined to determine the origins, structure and propagation mechanism of the spike. Figure 8 is representative of a type of plot that will be used frequently during the paper. The solid and dashed line traces at the top of the Figure show the static pressure at $10 \%$ of axial chord upstream of the leading edge (at the location indicated by the dotted line). The solid line is the instantaneous trace; the dashed line is the time-averaged trace (averaged in the relative frame over one rotor revolution immediately prior to stall inception). A line representing $0.5 \rho U_{t}^{2}$ is drawn on the right of the plot to provide a scale. Below these traces are contour plots of non-dimensional static pressure coefficient, $\widetilde{\Delta p}$, and radial component of vorticity, $\widetilde{\omega_{r}}$. Each blade is assigned a number shown at the bottom of the figure and time is indicated with reference to the accompanying pressure trace plot (Fig. 7) with $\tau$ indicating 


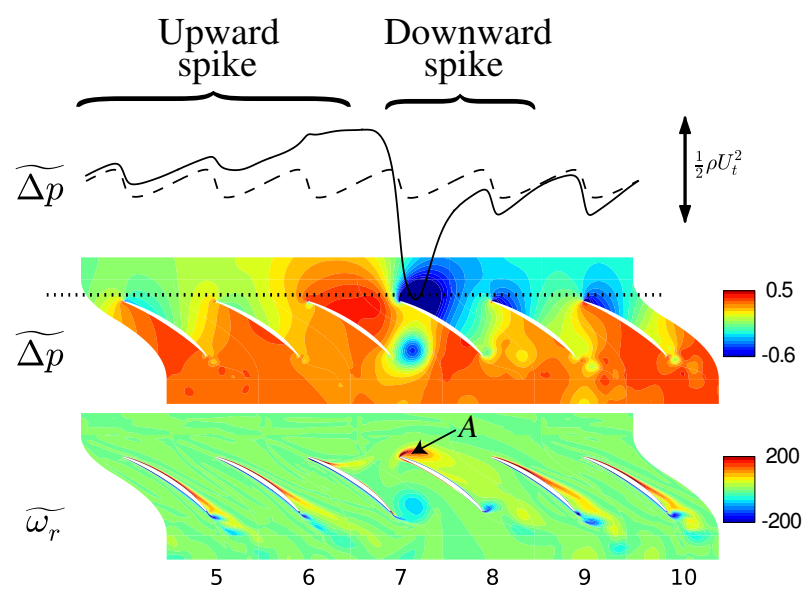

(a) $t=t_{2}$

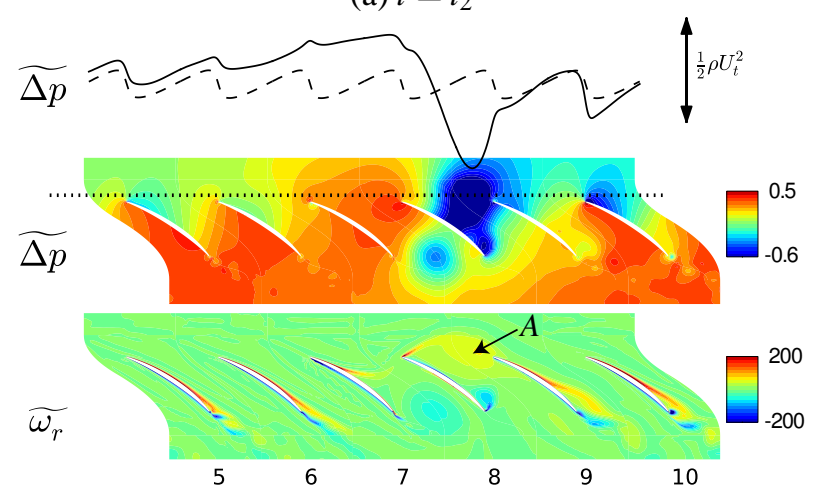

(b) $t=t_{2}+1.5 \tau$

FIGURE 9: Spike caused by leading edge separation in $2 \mathrm{D} \mathrm{E}^{3}$ tip profile cascade

the blade passing period.

Figure 8 shows the flow field associated with the initial disturbance at two time instants. The pressure trace deviates from the time-averaged value due to a perturbation in blade loading. In Fig. 8(a), the suction-surface boundary layers of blades 1 to 3 are separated at approximately mid-chord; the resultant blockage reduces the blade loading and the pressure upstream of the blades rises. The separation on blade 3 causes an increase in incidence on to blade 4; the resultant increase in leading edge loading causes a local reduction on the upstream pressure trace. The suction-surface boundary layer of blade 4 cannot sustain the required deceleration and separates, increasing the incidence on to blade 5, Fig. 8(b). In this way, the disturbance has propagated, by one blade pitch, in the way proposed by Emmons et al. [14].

The suction surface separations continue to propagate from blade to blade, moving away from the restaggered blades where they first occurred. The separations move further forward with each blade because of the following positive feedback mechanism: separation on one blade increases the incidence on to the next blade, causing an earlier separation on that blade, and so on. At the time shown in Fig. 9(a), the separation occurs close to the leading edge of blade 7 and at the leading edge of blade 8. The passage between blades 7 and 8 is almost completely blocked (causing the upward spike). The vorticity that is shed by the leading edge of blade 8 rolls up into a vortex (labelled ' $A$ ') that convects toward the leading edge of blade 9 in Figure 9(b) - the low pressure associated with this vortex is responsible for the sharp downward spike seen on the upstream trace. Once it arrives at blade 9, vortex 'A' triggers a new leading edge separation, causing a new shedding of vorticity and further growth of the spike. The propagation of the spike therefore includes the convection of shed vorticity from one blade to the next. In the relative frame, this means that the downward spike (the low pressure zone associated with the shed vortex) leads the upward spike (high pressure caused by the blocked passages). In the absolute frame, stationary pressure probes measure a positive pulse followed by a negative pulse.

The two-dimensional calculations thus show that leading edge separation is responsible for the spike. The spike propagates by the convection of the vortex that is shed from the leading edge. This will be shown to be the case in all the configurations presented in the paper. For this two-dimensional geometry, the high incidence responsible for the leading edge separation was caused by blockage from separated blade surface boundary layers.

\section{Full annulus, zero tip clearance}

We extend the preceding two-dimensional description to three dimensions and examine the actual $\mathrm{E}^{3}$ Rotor B blade. The first set of three-dimensional calculations to be shown are with zero tip clearance. While the setup is artificial because the casing is stationary (rather than rotating as in a shrouded rotor) it is a limiting case for the unshrouded rotor, providing a step upwards in complexity towards the full situation. A similar procedure to that followed for the two-dimensional computations was adopted: single passage unsteady simulations $\left(1.4 \times 10^{6}\right.$ nodes, 12 operating points) to obtain an approximate stability limit; quarter annulus (14 blades, 93 degrees) simulations $\left(19 \times 10^{6}\right.$ nodes, 2 operating points) with four restaggered blades to obtain the operating point at spike onset; full annulus $\left(74 \times 10^{6}\right.$ nodes, 2 operating points) simulations to be certain that the spike development and propagation is unaffected by the imposition of a 4-per-rev repeating sector of 1 degree increased incidence.

Figure 10 shows simulated time traces from six static pressure probes arranged around the casing circumference at $10 \%$ of axial chord upstream of the rotor leading edge. The similarities between this plot and that of the two-dimensional linear cascade of tip section profiles (Fig. 7) can be seen. The initial perturbation to the regular upstream potential field of the blades is seen at $t_{1}$. Within half of a rotor revolution, this disturbance has formed a spike, (time $t_{2}$, location ' $\mathrm{Y}$ ').

In the same manner as the two-dimensional case, the per- 


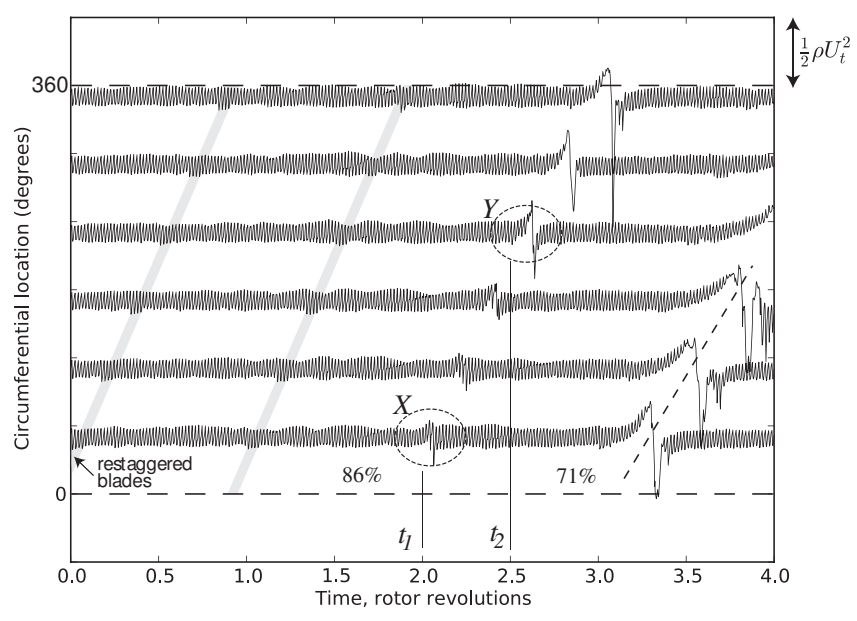

FIGURE 10: Spike stall inception in $\mathrm{E}^{3}$ rotor computation, zero clearance
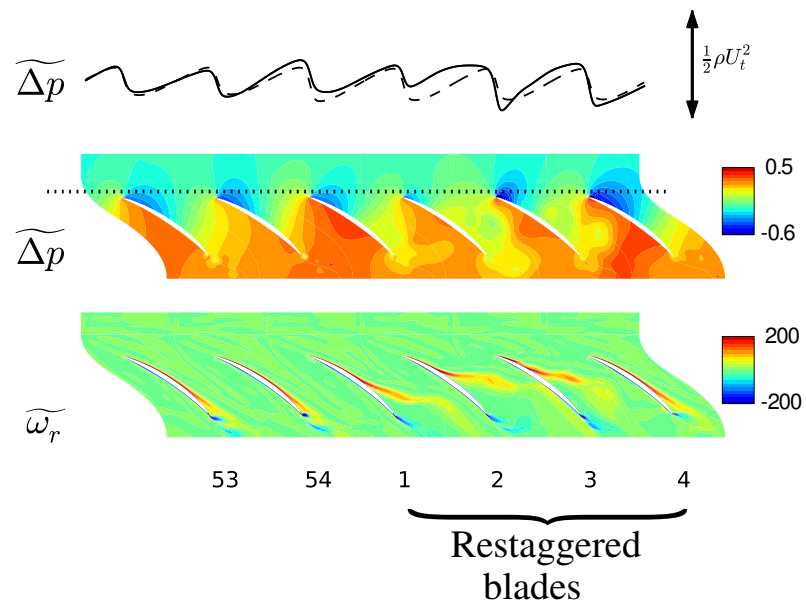

$$
t=t_{1}=2.0 \text { revs }
$$

FIGURE 11: Blade loading perturbation caused by growth of corner separation in $\mathrm{E}^{3}$ rotor, zero clearance, $95 \%$ span

turbation to the blade loadings in zone ' $\mathrm{X}$ ' of Fig. 10 is caused by separation from the blade suction surface that occurs first on the restaggered blades, Fig. 11. In common with all similar plots from three-dimensional simulations shown in this paper, the flow field and pressure traces in Fig. 11 are from a cut at 95\% span so the separation shown is actually a slice through a three-dimensional corner separation. Blockage from the corner separations on blades 1 and 2 causes the upward spike in the upstream pressure trace. The high incidence on blade 3 results in high leading edge loading and a small downward spike in the pressure trace.

The first separation from the leading edge of a blade is seen in Fig. 12(a) and occurs at blade 6 . The shed vorticity rolls up into vortex ' $\mathrm{B}$ ' that convects toward, and in front of, the leading edge of blade 7 . Here, as was the case in the two-dimensional simulations, the vortex triggers a new leading edge separation

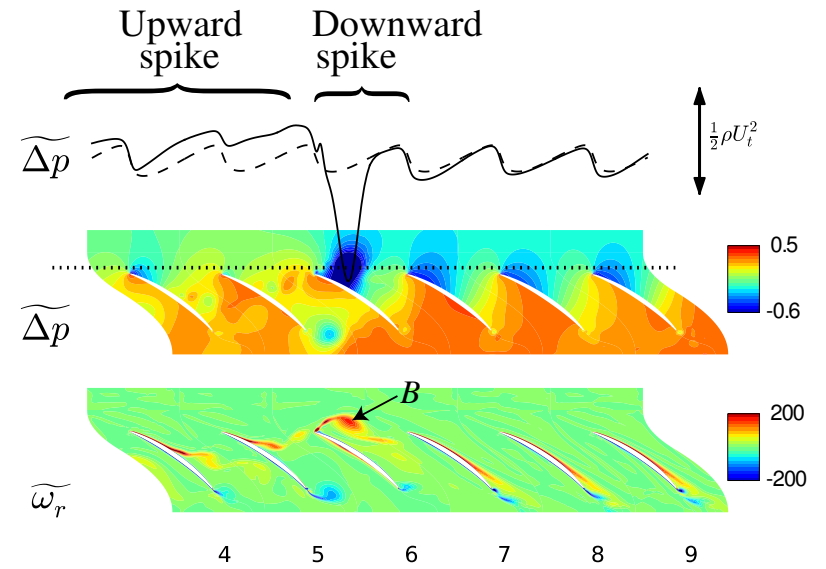

(a) $t=t_{2}=2.48$ revs

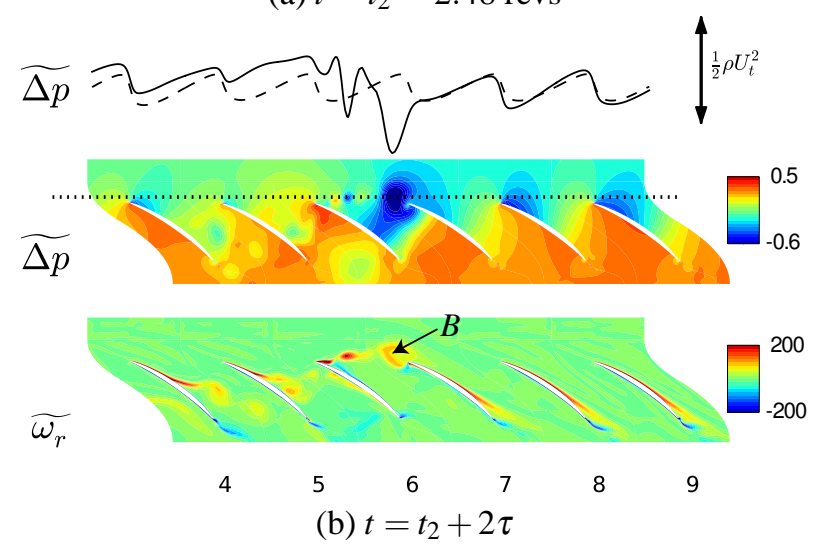

FIGURE 12: Spike caused by leading edge separation in $\mathrm{E}^{3}$ rotor, zero clearance, $95 \%$ span

(from blade 7) and vorticity will be shed so as to reinforce that which has travelled from blade 6 .

The key difference, as regards the spike structure, between the two-dimensional cascade and the full blade row is the spanwise extent of the leading edge separation. To illustrate this, a sequence of snapshots of blade 6 showing an iso-surface of the $\lambda_{2}$ vortex criterion ( [15]) is presented in Fig. 13. The $\lambda_{2}$ iso-surface can be regarded as a marker for vorticity associated with discrete swirling flow structures (i.e. vortices) rather than vorticity in a sheet or shear layer (a boundary layer, for example). Thus, even though vortex lines cannot end in a fluid, the $\lambda_{2}$ surfaces can do so. The final snapshot in the series of three, Fig. 13(c) is at the same time instant as Fig. 12(a); two preceding time instances are also shown so that the development of the structure can be observed.

Figure 13(a) shows that the non-uniform incidence, greatest at the tip, has caused a leading edge separation (circled in the Figure) to form over the outer $25 \%$ of span of blade 6 . In Fig. 13(b), the vorticity shed from the blade by this separation has formed a vortex-tube. The vortex tube appears to terminate at the casing and at the suction-surface because the vortex fila- 


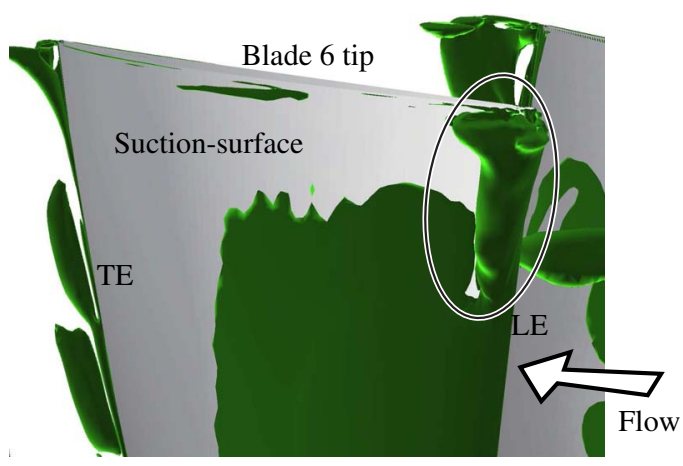

(a) $t=t_{2}-\tau$; leading edge separation circled

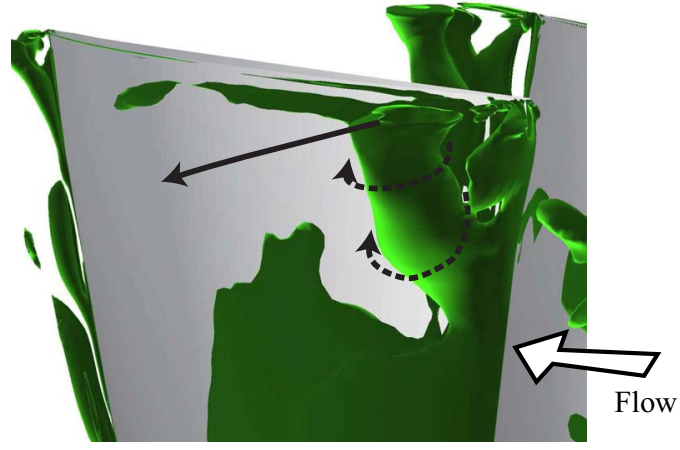

(b) $t=t_{2}-0.5 \tau$; vortex tube forms, upper end moves circumferentially along casing

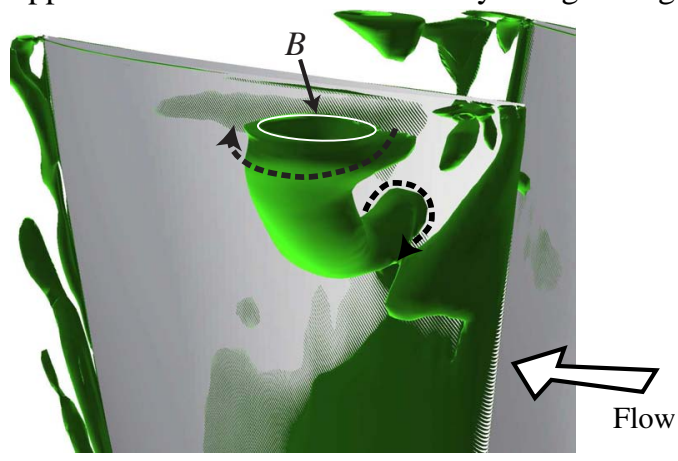

(c) $t=t_{2}$; lower end of tube moves downstream along suction-surface

FIGURE 13: Structure of the spike. Iso-surface of the $\lambda_{2}$ vortex criterion, $\mathrm{E}^{3}$ rotor zero clearance

ments become tangential to the solid surfaces in a layer and are thus not indicated by the $\lambda_{2}$ criterion. The rotation of the vortex tube is indicated by the dashed arrows, and the convection of the casing end of the tube in the circumferential direction toward the pressure-side of the adjacent blade, is also shown. Finally, in Fig. 13(c), the suction-surface end of the tube is seen to be moving in a streamwise direction toward the trailing edge of the blade.

The motion of the vortex tube is therefore summarised as follows. The end of the tube at the casing moves circumferentially toward the leading edge of blade 7 , where it triggers a new leading edge separation and is enhanced by the addition of new vorticity; the end on the suction-surface of blade 6 proceeds downstream towards the trailing edge. This is evidence for the structure shown in Figs. 4 and 5. We note again the resemblance of this structure to that proposed by Inoue et al. $[10,16,17]$ as an explanation for rotating disturbances seen in their compressor, and that computations by Inoue et al. [18], for a different compressor, also showed a similar vortex tube.

The calculations of the $\mathrm{E}^{3}$ Rotor $\mathrm{B}$ with zero clearance show the same mechanisms for spike, and its propagation, as in the two-dimensional simulations. The spike is a leading edge separation over the outer $25 \%$ of span that causes vorticity to be shed. The resulting vortex tube has one end at the casing - this convects to the leading edge of the next blade in the same way as the vortex in the two-dimensional simulations - and one on the suction surface which travels downstream. For this three-dimensional, zero clearance, geometry, the high incidence responsible for the leading edge separation was caused by blockage from separated blade surface boundary layers.

\section{Full annulus, with tip clearance}

The final set of computations of the $\mathrm{E}^{3}$ Rotor $\mathrm{B}$ were performed with a tip clearance of $1.8 \%$ of chord. The computational procedure and run times for this set of simulations were similar to those described above for the zero clearance case.

Approaching stall As the $\mathrm{E}^{3}$ rotor is throttled toward stall, the interface line that demarcates the oncoming flow from the over-tip leakage flow rotates toward the circumferential direction until, just before stall, it is almost coincident with the leading edge plane. This is illustrated by the time-averaged entropy contours, at $95 \%$ span, shown in Fig. 14. The operating point shown is stable.

It is also found that the tip clearance flow is highly unsteady, as has been observed by others, [19,20]. Figure 14 shows instantaneous contours of radial vorticity at the same operating point. The vortex filaments of the tip leakage vortex, which have no radial component at the exit of the tip gap, deform to produce a series of islands of positive and negative radial vorticity which convect across the passage. Low pressure regions associated with these structures were measured by Young et al. [21] on the casing of the large tip gap portion of their axial compressor with eccentric clearance.

At stall Figure 15 shows simulated casing static pressure traces as the $\mathrm{E}^{3}$ rotor with tip clearance is brought into stall. When compared with the pressure traces from the twodimensional and zero clearance cases, two points are apparent. First, there are many disturbances to the regular blade passing signal (particularly narrow low pressure troughs) prior to the final emergence of a spike. Second, the circumferential location 

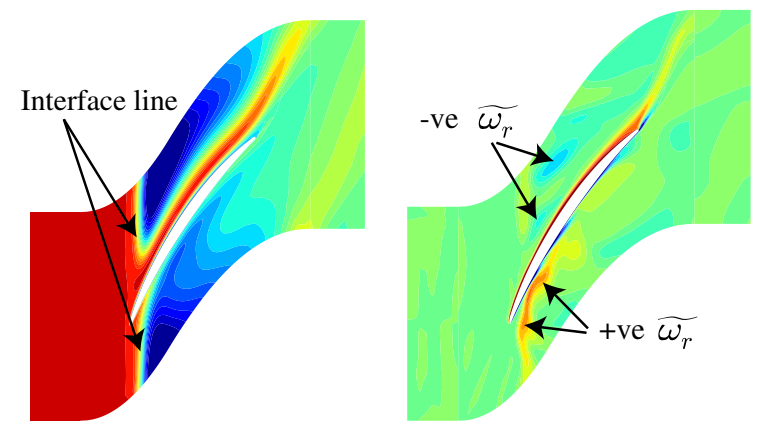

FIGURE 14: Circumferential interface line shown by timeaveraged entropy (left); unsteady tip leakage flow shown by instantaneous radial vorticity (right). $\mathrm{E}^{3}$ rotor with tip clearance, last stable operating point before stall, $95 \%$ span

of the emergence of spikes is not determined by the restaggered blades and, linked to this, more than one spike is seen. The cause of both of these points will be shown to be the tip clearance flow and, specifically, the unsteadiness of the tip clearance flow.

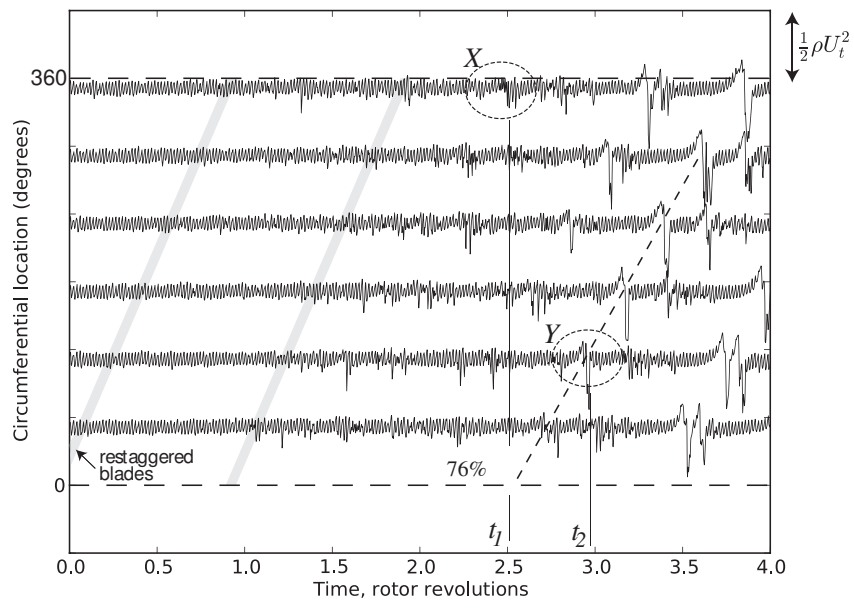

FIGURE 15: Spike stall inception in $\mathrm{E}^{3}$ rotor computation, with tip clearance

Figure 16(a) shows a disturbance that later becomes a spike (zone ' $X$ ' in Fig. 15). In contrast to the two-dimensional and zero clearance cases, no separations are visible on the rear suction surfaces. Instead, it is the tip clearance flow that provides the incidence necessary for leading edge separation. The interface line between the on-coming flow and the tip leakage flow, as delineated by the islands of radial vorticity, is approximately parallel with the leading edge plane. When the tip clearance flow from one blade reaches the leading edge of the next, the incidence is very high (the flow is essentially tangential) and a leading edge separation results. However, because the clearance flow is itself unsteady, immediately prior to spike stall there will be many momentary leading edge separations that are not large enough

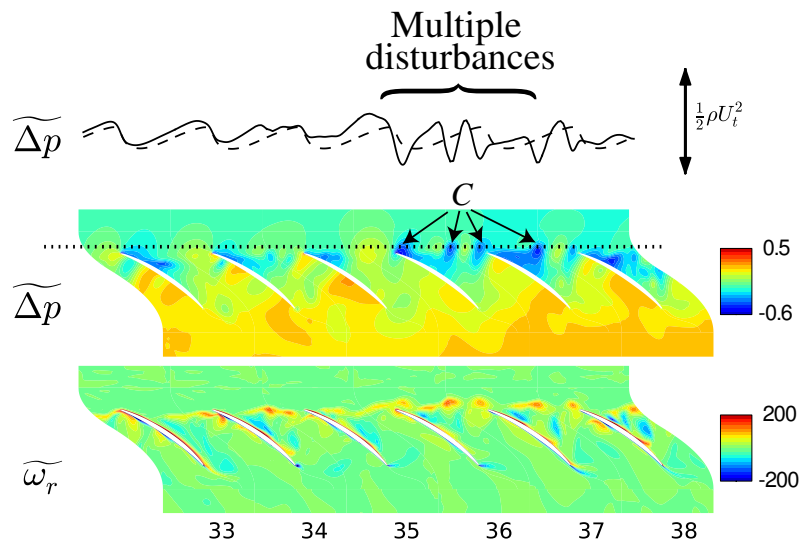

(a) $t=t_{1}=2.50$ revs, multiple leading edge separations
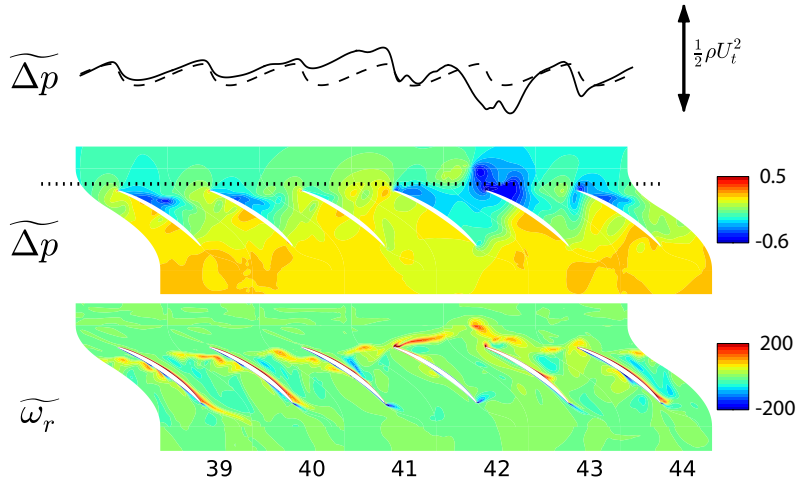

(b) $t=t_{2}=2.94$ revs, leading edge separation causing a spike

FIGURE 16: Spike formation in $\mathrm{E}^{3}$ rotor, with clearance, $95 \%$ span

spatially, or temporally, to convect to the next blade and trigger a new separation - this is the cause of the multiple disturbances seen in Fig. 15. In addition, if the fluctuations in incidence from the unsteady leakage jet are more than 1 degree in amplitude, the restaggered blades will not provide a trigger for the emergence of a spike. In Fig. 16(a), several vortices have formed from leading edge separations on blades 36 and 37 (labelled 'C'). It is not easy to discern from the snapshot shown in Fig. 16(a), but the pressure traces in Fig. 15 indicate that these separations are the early signs of a "successful" spike.

Although the initial stages of spike formation differ for the $\mathrm{E}^{3}$ case with clearance compared to the preceding twodimensional and zero clearance cases, the structure and propagation of the spike, Fig. 16(b), is the same. Leading edge separation causes the shedding of vorticity which convects to, and in front of, the adjacent blade where it triggers a new leading edge separation.

The computations of the $\mathrm{E}^{3}$ rotor with tip gap show that leading edge separation is again responsible for the spike. The cause of the high incidence that leads to this separation is not, however, a growing corner separation but, instead, the tip leakage flow from the adjacent blade. Prior to stall, the unsteadiness of 
this tip leakage flow causes multiple transitory leading edge separations that do not survive (i.e. do not convect in front of the adjacent blades) to form a spike.

\section{Summary of $E^{3}$ calculations}

All three cases of the $\mathrm{E}^{3}$ geometry exhibit the same mechanism of spike formation and propagation. In each case, flow separation from the leading edge results in shed radial vorticity which convects to the leading edge of the adjacent blade, triggering a new separation. The principal difference between the simulations is the cause of the incidence that precipitates the leading edge separation. For the two-dimensional and zero clearance cases, the incidence is caused by the blockage from rear suction surface or corner separations. For the case with tip clearance, the incidence is caused by the impingement of the tip leakage flow from the adjacent blade. It is plausible that a rotor with a weaker tip clearance flow (for example due to a smaller tip gap) may exhibit corner separations and behave in a similar manner to the zero clearance case. Whatever the particular circumstances that promote high incidence in a given compressor, separation from the leading edge is seen to be the common factor in the structure and propagation of the spike.

\section{CAMBRIDGE LOW SPEED COMPRESSOR}

To provide experimental verification of the structures and mechanisms discerned from the $\mathrm{E}^{3}$ computations, a series of tests were performed on a low speed single stage compressor at the University of Cambridge. Details of the machine are given by Young et al. [21] and are summarised in Table 2.

\begin{tabular}{|l|c|}
\hline Design flow coefficient $V_{x} / U_{t}$ & 0.44 \\
Design stage pressure rise coefficient $\Delta p_{0} / 0.5 \rho U_{t}^{2}$ & 0.44 \\
Hub to tip radius ratio $r_{h} / r_{t}$ & 0.75 \\
Tip diameter & $488 \mathrm{~mm}$ \\
Number of rotors & 58 \\
Rotational speed & $2980 \mathrm{rpm}$ \\
\hline
\end{tabular}

TABLE 2: Design parameters for the Cambridge compressor

The compressor operated with a tip clearance of $1.4 \%$ chord. An axial array of 5 pressure transducers, covering the region $-0.4 \leq x / c_{x} \leq+0.4$ was installed at one circumferential location. 8 additional sensors were placed around the annulus to track stall development. To compare with the experimental data, computations were run on the stage using the procedure described in the Appendix. Results from the quarter annulus (14 rotor passages, $33 \times 10^{6}$ node) computations are reported here (experience with the $\mathrm{E}^{3}$ rotor showed the mechanisms of the initial development of the spike are the same for the quarter and full annulus computations.)

Figure 17 shows measured and calculated total-to-static pressure rise characteristics. As for the $\mathrm{E}^{3}$ characteristics, Fig. 6, the machine stalls on a negative slope and the quartercircumference (87 degrees in this case) sector computations stall at a higher flow coefficient than those for the single passage. The overall shape of the computed characteristic agrees well with the experiment with the flow coefficient at stall from the simulations 0.01 higher than the measured value.

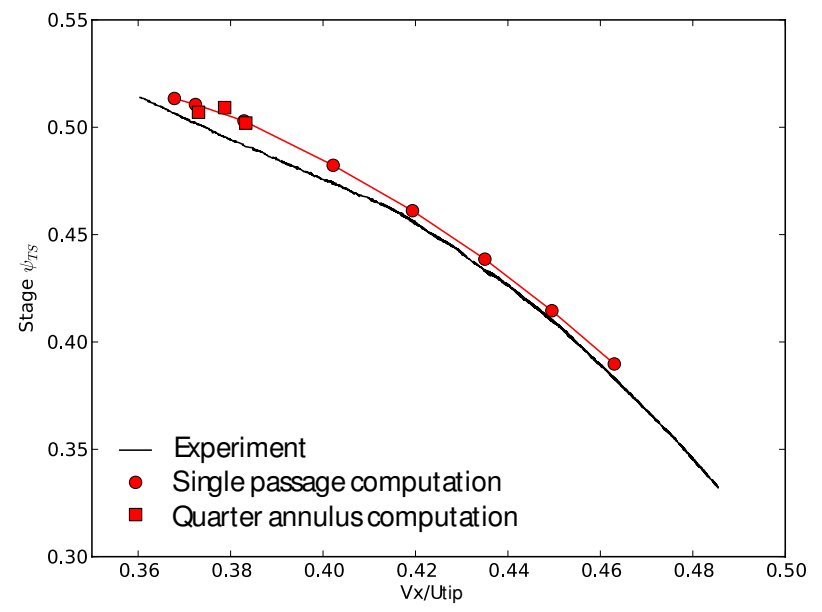

FIGURE 17: Measured and computed total-to-static pressure rise characteristics for the Cambridge compressor

Figure 18 depicts the early stages of spike development. There is a good agreement, both qualitative and quantitative, between the CFD and the experimental data. Note that the experiments show data from 10 blades as they move past the stationary pressure transducers, whereas the CFD is an instantaneous view of 10 blades. The computations show that the same mechanism observed in the $\mathrm{E}^{3}$ calculations is responsible for the formation of the spike: leading edge separation initiated by high incidence caused by the tip leakage flow. The interface line in the computations is again delineated by islands of vorticity indicating unsteadiness in the tip clearance flow.The intermittent leading edge separation seen in the $\mathrm{E}^{3}$ simulations with tip clearance is also present, but the small spatial extent of the vortices make them hard to discern in the measurements. One such event is detected at ' $D$ ' and the reduced loading associated with leading edge separation on the preceding blades, ' $\mathrm{E}$ ', is also apparent.

At the later time depicted in Fig. 19, the experiments and computations show a spike. A large low pressure region associated with a leading edge separation is seen at ' $F$ '. The location of this region, including the low pressure zone further aft in the preceding blade passage, is well reproduced by the computations. 


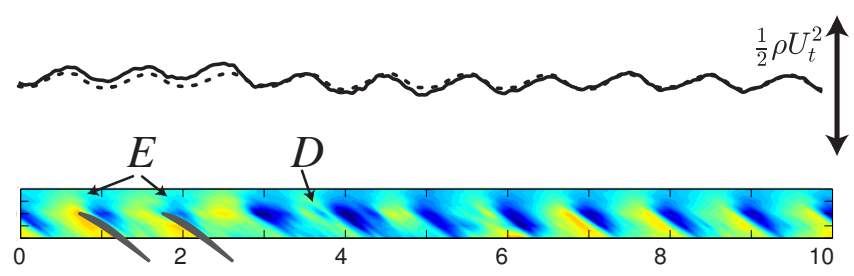

(a) Experimental data: casing $\widetilde{\Delta p},-0.4 \leq x / c_{x} \leq+0.4$
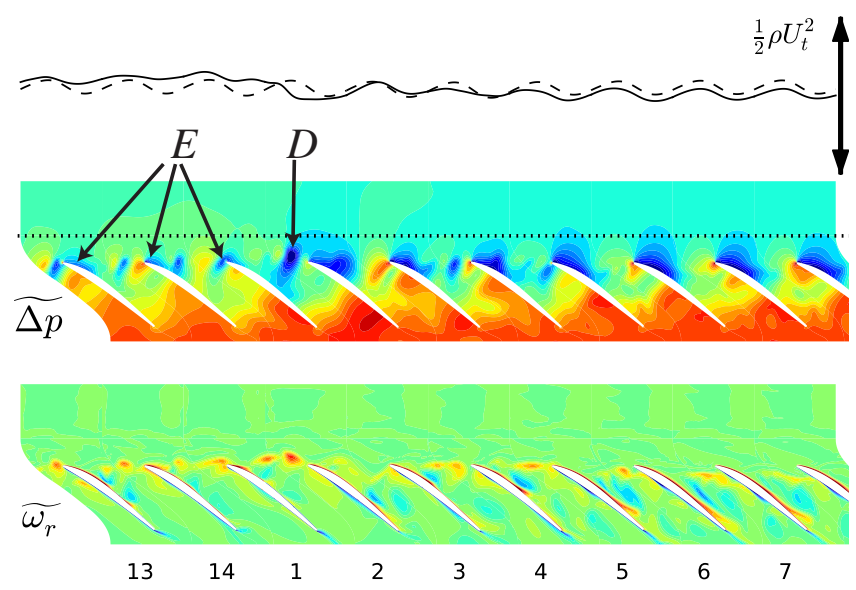

(b) CFD: traces of $\widetilde{\Delta p}$ at $x / c_{x}=-0.4$, contours of $\widetilde{\Delta p}$ (top) and $\widetilde{\omega}_{r}, 95 \%$ span

FIGURE 18: Earliest detection of leading edge separations in the Cambridge compressor

The measurements and simulations also show that small islands of vorticity, 'G', are apparent in the preceding passages (blades 1 to 3 in the computations). The trajectory of the vortices labelled ' $G$ ' indicates that blades 1 to 3 are separated at the leading edge and the associated blockage is responsible for the upward spike.

The level of agreement between the experiments and computations in terms of overall pressure-rise characteristic, pressure traces upstream of the rotor, and detailed casing flow field data provides strong corroborating evidence for the structures and propagation mechanism of spike-type stall inception seen in the $\mathrm{E}^{3}$ computations.

\section{SUMMARY AND CONCLUSIONS Overall Findings}

1. Numerical simulations and experimental measurements have been used to explain the origins, structure and propagation mechanism of spike-type disturbances in rotating stall inception. The general features of spike formation are found to be similar in two-dimensional cascades, axial compressor stages with rotor tip clearance and with rotor tip shrouds, and vaned diffusers in centrifugal compressors. In all these geometries, spikes originate from flow separation near the blade leading edge on the suction side, which results in vor-

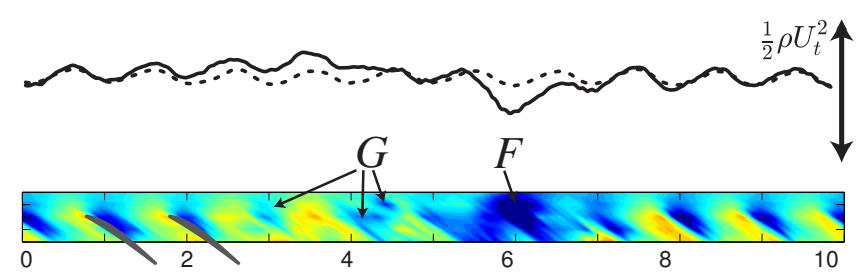

(a) Experimental data: casing $\widetilde{\Delta p},-0.4 \leq x / c_{x} \leq+0.4$
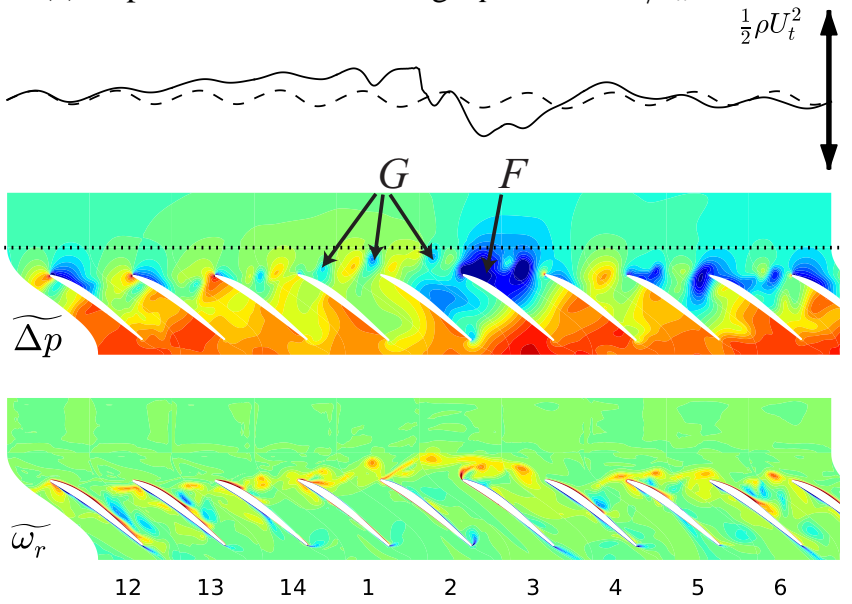

(b) CFD: traces of $\widetilde{\Delta p}$ at $x / c_{x}=-0.4$, contours of $\widetilde{\Delta p}$ (top) and $\widetilde{\omega}_{r}, 95 \%$ span

FIGURE 19: Spike caused by leading edge separations in the Cambridge compressor

tex formation and propagation around the annulus.

2. The description of spike behavior given here aligns with early ideas put forward by Emmons et al. [14], adding depth and quantitative information to his incidence based mechanism, and by Inoue et al. [10], who initially suggested the involvement of leading edge vortices in cell formation. The results in the paper show that the description proposed is consistent with both the numerical simulations and the experiments for compressors with a range of differing blade parameters.

\section{Specific Findings}

1. Spike-type stall inception involves localized disturbances, of blade passage scale, which propagate from blade to blade around the annulus. The origins of a spike involve radial vorticity, which is shed when flow separates from the leading edge of a blade and then rolls up into a discrete vortex of sub-passage proportions. The vortex convects circumferentially towards, and then in front of, the leading edge of the next blade, which experiences increased incidence and then separation and the formation of a new vortex. The vorticity shed by the second blade is reinforced by that from the first so, at least in the initial stages, the disturbance will grow as 
it propagates. The pattern of separation, vortex formation, translation, new blade flow separation and renewed vortex formation, explains the structure and propagation mechanism of the spike.

2. During stall onset, flow separation at the leading edge causes a reduction of blade lift and a local increase in static pressure upstream of the blade row with circumferential extent of a few blade pitches. This localised pressure rise generates the upward pressure spike associated with this type of disturbance.

3. The shed vortex which accompanies the loss of lift gives rise to a region of low static pressure on the compressor casing. The resulting pattern of a region of high pressure adjacent to a region of low pressure gives rise to the typical up-down signature of a maturing spike seen in pressure signal recorded upstream of the rotor.

4. The experimental and computational results agree and they suggest that spike formation is not dependent on tip leakage flow. More precisely the vortex described above is not associated with the tip leakage flow in that the same general features are observed in blade rows with and without tip clearance. In cases where tip clearance is present, as in a conventional axial compressor, the leakage flow contributes to high incidence at the rotor tips, but the leakage flow itself is not a requirement for flow separation and spike formation.

5. The fluid dynamic processes that give rise to the incidence that creates the initial leading edge separation depend on the details of the blades being used. For a two-dimensional cascade, the separation process begins at the trailing edge of the blade and works its way towards the leading edge. In a three-dimensional case without tip clearance, corner separation can play a part in triggering separation at the leading edge. In a conventional blade row with tip clearance, leakage flow can sometimes exacerbate leading edge incidence. In all cases, however, regardless of the precise cause of increased incidence, spike development is due to leading edge flow separation and vortex formation.

\section{Acknowledgements}

The authors gratefully acknowledge the contributions made by several individuals during many discussions on the topics described in this paper, including those provided by C. Freeman and S.A. Weichert of the Whittle Laboratory, N.A. Cumpsty of Imperial College, and J.J. Adamczyk. The authors would also like to thank S. Aoki, S. Uchida and E. Ito of MHI for their support during the project; J.J. Bolger of Rolls-Royce for supplying the geometry of the Cambridge Low Speed Compressor and for supporting the associated experimental programme; and $\mathrm{M}$. Brand and A. Kottapalli for taking the data on the MIT shrouded compressor.

\section{APPENDIX - DETAILS OF THE COMPUTATIONAL AP- PROACH}

All the computations presented in this paper were performed using Turbostream. The code is a structured multi-block RANS solver that was developed using the method employed in the Denton code, TBLOCK. The approach is finite-volume timemarching, second order in space, with three levels of multigrid and a single step explicit time integration scheme. All simulations presented here used the Spalart-Allmaras turbulence model with adaptive wall functions and had fully turbulent boundary layers. All the runs were second order accurate in time using Jameson's dual timestepping technique, with 72 physical time steps per blade passing period.

The principal feature of Turbostream is its speed. As well as running on conventional CPUs, the code is also optimized to run on clusters of graphics processing units (GPUs). Turbostream runs 10 to 20 times faster on one GPU as compared to all cores of a contemporaneous CPU. This allowed an operating point of the quarter annulus $\left(\approx 20 \times 10^{5}\right.$ node) calculations to be completed in one day on 32 GPUs.

The grids were generated using a Mitsubishi Heavy Industries in-house code that produced elliptically smoothed blade row meshes with $\mathrm{H}-\mathrm{O}-\mathrm{H}$ topology. Tip gaps were solved with two additional blocks (O-H topology) with 11 points in the gap. All blades were meshed with $293 \times 37 \times 74$ points in the O-mesh, with approximately 30 points around the leading edge, and typical $y^{+}$values were below 5 on the blade surfaces. The computational domain extended 1.5 tip radii upstream and downstream of the blade rows. This gave an axial distance of approximately one quarter of a circumference between the compressor and the planes at which inlet or outlet boundary conditions were imposed. This was verified to be acceptable by comparing the solutions obtained for the two-dimensional linear cascade with those for the same cascade but with inlet and exit boundaries placed at 6 tip radii away from the blades. To reduce the mesh count required, the pitchwise node count per passage was reduced from 57 at the blade row, to 15 at the domain boundaries in 3 stages.

At the inlet of the domain, the total pressure and total temperature were specified as uniform. However, a portion at the start of the inlet duct was set to have zero skin friction in order to control the inlet endwall boundary layer thickness. The boundary layer thickness was matched to measurement data for the Cambridge compressor. At the exit of the domain, a convergent nozzle was employed to provide the compressor with a back-pressure that changes with mass flow rather than a fixed pressure boundary condition ( [22]). The nozzle was not choked, so that altering the pressure downstream of the nozzle (specified to be uniform) caused the compressor operating point to change and the pressure upstream of the nozzle to vary according to the matching of the compressor characteristic and the characteristic of the nozzle.

Each operating point was run for five flow-through times 
(from domain inlet to exit); this was of the order of 4 rotor revolutions. Over the first rotor revolution, the back pressure at the exit of the nozzle was increased linearly with time and the flow coefficient typically reduced by 0.01 . This procedure was done first with a single passage domain to obtain the approximate stall point, then with a quarter annulus domain, and finally with a full annulus.

Post-processing is a formidable task with unsteady datasets of order $10^{8}$ nodes. The approach taken was similar to that of the experimentalist. Several measurement planes were output 12 times per rotor passing period, e.g. a selection of blade-to-blade planes, rotor blade surface, and rotor exit planes. From these, a particular range of times was identified for deeper analysis and the operating point was then re-run to obtain this data.

\section{REFERENCES}

[1] Camp, T., and Day, I., 1998. "A study of spike and modal stall phenomena in a low-speed axial compressor". ASME J. Turbomach., 120.

[2] Garnier, V., Epstein, A., and Greitzer, E., 1991. "Rotating waves as a stall inception indication in axial compressors". ASME J. Turbomach., 113.

[3] Lin, F., Chen, J., and Meilin, L., 2004. "Wavelet analysis of rotor-tip disturbances in an axial-flow compressor". AIAA J. Propulsion Power, 20.

[4] Deppe, A., Saathoff, H., and Stark, U., 2005. "Spike-type stall inception in axial-flow compressors". In 6th European Conference on Turbomachinery.

[5] Weichert, S., 2011. "Tip clearance flows in axial compressors: stall inception and stability enhancement". $\mathrm{PhD}$ thesis, University of Cambridge.

[6] Brand, M., Kottapalli, A., and Spakovszky, Z., 2011. The dependence of spike-type stall inception on blade-tip leakage flow in axial compressors. Tech. rep., 16.62X final report, experimental projects course, Department of Aeronautics and Astonautics, MIT, May.

[7] Spakovszky, Z., and Roduner, C., 2009. "Spike and modal stall inception in an advanced turbocharger centrifugal compressor". ASME J. Turbomach., 131.

[8] Everitt, J., and Spakovszky, Z., 2011. "An investigation of stall inception in centrifugal compressor vaned diffusers". ASME IGTI Turbo Expo, GT2011-46332.

[9] Vo, H., Tan, C., and Greitzer, E., 2008. "Criteria for spike initiated rotating stall”. ASME J. Turbomach., 130.

[10] Inoue, M., Kuroumaru, M., Tanino, T., and Furukawa, M., 2000. "Propagation of multiple short-length-scale stall cells in an axial compressor rotor". ASME J. Turbomach., 122.

[11] Brandvik, T., and Pullan, G., 2011. "An accelerated 3d navier-stokes solver for flows in turbomachines". ASME J. Turbomach., 133.

[12] Pullan, G., Denton, J., and Curtis, E., 2006. "Improving the performance of a turbine with low aspect ratio stators by aft-loading". ASME J. Turbomach., 128.

[13] Wisler, D., 1977. "Core compressor exit stage study: Volume 1 - blading design". NASA CR-135391.

[14] Emmons, H., Pearson, C., and Grant, H., 1955. "Compressor surge and stall propagation". Trans. ASME, 79.

[15] Jeong, J., and Hussain, F., 1995. "On the identification of a vortex”. J. Fluid Mechanics, 285.

[16] Inoue, M., Kuroumaru, M., Tanino, T., Yoshida, S., and Furukawa, M., 2001. "Comparative studies on short and long length-scale stall cell progatating in axial compressor rotor". ASME J. Turbomach., 123.

[17] Inoue, M., Kuroumaru, M., Yoshida, S., and Furukawa, M., 2002. "Short and long length-scale disturbances leading to rotating stall in an axial compressor stage with different stator/rotor gaps". ASME J. Turbomach., 124.

[18] Inoue, M., Kuroumaru, M., Yoshida, S., Minami, T., Yamada, K., and Furukawa, M., 2004. "Effect of tip clearance on stall evolution process in a low-speed axial compressor stage". ASME IGTI Turbo Expo, GT2004-53354.

[19] Mailach, R., Lehmann, I., and Vogeler, K., 2001. "Rotating instabilities in an axial compressor originating from the fluctuating blade tip vortex". ASME J. Turbomach., 123.

[20] März, J., Hah, C., and Neise, W., 2002. "An experimental and numerical investigation into the mechanisms of rotating instability". ASME J. Turbomach., 124.

[21] Young, A., Day, I., and Pullan, G., 2011. "Stall warning by blade pressure signature analysis". ASME IGTI Turbo Expo, GT2011-45850.

[22] Vahdati, M., Sayma, A., Freeman, C., and Imregun, M., 2005. "On the use of atmospheric boundary conditions for axial-flow compressor stall simulations". ASME J. Turbomach., 127. 